\title{
EUROPEAN UNIVERSITY INSTITUTE
}

DEPARTMENT OF ECONOMICS

EUI Working Paper ECO No. 99/27

Integration, Agglomeration and the Political Economics of Factor Mobility

Gianmarco I.P. Ottaviano

and

JACQUES-FranÇOIS ThISSE 


\begin{abstract}
All rights reserved.
No part of this paper may be reproduced in any form without permission of the author.
\end{abstract}

(C)1999 G.I.P. Ottaviano and J.-F. Thisse

Printed in Italy in July 1999

European University Institute

Badia Fiesolana

I-50016 San Domenico (FI)

Italy 


\title{
Integration, agglomeration and the political economics of factor mobility*
}

\author{
Gianmarco I.P. Ottaviano ${ }^{\dagger}$ and Jacques-François Thisse ${ }^{\ddagger}$
}

16 June 1999

\begin{abstract}
This paper tackles the issue of the optimality of agglomeration in a two-region economy with skilled/mobile and unskilled/immobile workers. The market leads to the optimal outcome when transport costs are high or low. However, for intermediate values, it yields agglomeration whereas dispersion is socially desirable. We show that competitive lobbying on factor mobility by the two groups of workers sustains the second best optimum.
\end{abstract}

${ }^{*}$ We should like to thank Pierpaolo Battigalli, Giuseppe Bertola, Michel Lebreton, Philippe Martin, Massimo Motta, Victor Norman and seminar participants at NHH Bergen and EUI Florence for useful comments and discussions. We are indebted to FNRS (Belgium) for funding. The first author also gratefully aknowledges financial support from a Jean Monnet Fellowship at EUI Florence.

${ }^{\dagger}$ Università di Bologna, EUI, CORE-Université Catholique de Louvain and CEPR

${ }^{\ddagger}$ CORE-Université catholique de Louvain, CERAS-Ecole nationale des ponts et chaussées and CEPR 


\section{Introduction}

One of the most severe challenges posed by the ongoing integration of national economies within the European Union is the strengthening of the core regions accommodating modern production sectors at the expense of the peripheral regions retaining only traditional and local activities (Ottaviano and Puga, 1998). In the First Report on Economic and Social Cohesion, the European Commission observes that "[t]he average disparity in income per head in the $\mathrm{EU}$ is twice that in comparable regions in the US", while "[e] conomic activity is strongly concentrated in the most urbanised areas of the Community. Regions with more than 500 inhabitants per square kilometers account for only $4 \%$ of the land area of the Union but for more than half the population. This implies that between two thirds and three quarters of the EU's total wealth creation occurs in urban areas" (p.24).

Although Sala-i-Martin (1996) has found slow interregional convergence from 1950 to 1990, it is more and more widely accepted that regional disparities have been growing within the EU since the deepening of the integration process started in the 1980s (Amstrong and Vickerman, 1995; Neven and Goyette, 1995; Magrini, 1999). Furthermore, even slow convergence between countries may well hide a process of regional divergence inside each country as argued by de la Fuente and Vives (1995) who show that about half of the income inequality across EU regions corresponds to differences within each member state. Taking a different angle and comparing the spatial distributions of activities in various sectors between 1968 and 1990, Amiti (1998) notes both an increase in the geographical concentration of economic activities within most EU state members and, for a vast majority of sectors, a tendency toward more agglomeration within the $\mathrm{EU}$ as a whole. ${ }^{1}$

This lack of cohesion in social development and economic growth has led the European Commission to pay more attention to this issue at the time of the Single European Act (SEA). The reform of the Structural Funds and the creation of the Cohesion Funds, both aiming partially at the reduction of

\footnotetext{
${ }^{1}$ Comparing the relative importance of the Heckscher-Ohlin theory to that of economic geography, Davis and Weinstein (1999) observe that the latter provides a much better explanation of the spatial distribution of economic activity within a country such as Japan. To the extent that the EU is getting more and more integrated, the scenario of the core-periphery model might well become realistic if the mobility of some factors rises whereas trade costs simultaneously fall.
} 
regional disparities, have been the concretization of this awareness. For the period 1994-1999, these funds correspond to approximately one third of the EU budget, thus showing the growing importance that the 'regional question' plays for the European construction. For the European Commission (1996, p.13):

"Imbalances do not just imply a poorer quality of life for the most disadvantaged regions and the lack of life-chances open to their citizens, but indicate an under-utilisation of human potential and the failure to take advantage of economic opportunities which could benefit the Union as a whole."

The statement is clear-cut and reveals that the concern of the Commission is twofold. On the one side it is about equity (" ... a poorer quality of life for the most disadvantaged regions and the lack of life-chances open to their citizens ...”). On the other it is also about efficiency (“... an under-utilization of human potential and the failure to take advantage of economic opportunities which could benefit the Union as a whole..."). However, while the equity implications of regional imbalances are self-evident, the self-confidence of the statement about efficiency is puzzling. The reason why is the shortage of theoretical arguments on the emergence, not to say on the welfare impact, of regional imbalances that might support the Commission's view.

Indeed, if anything, conventional wisdom supports the opposing view, according to which the concentration of means within the most productive regions is often the optimal strategy to maximize global income (Rahman, 1963; Takayama, 1967). Accounting for regional disparities mitigates such recommendation but does not upset them: important discrepancies are usually required between the beginning and the end of the planning period because it is desirable in the meantime to invest into the most efficient regions (Michel et al., 1983). Thus, conventional wisdom seems to accept the existence of an inherent trade-off between regional equity and efficiency (Martin, 1998).

This paper has two objectives. The first is to investigate the conditions under which, as the Commission sustains, the equity-efficiency trade-off does not exist, i.e. agglomeration is indeed socially undesirable. In doing so, we are forced to depart from the neoclassical world of non-increasing returns to scale and perfect competition where economic integration has no dramatic effects on the spatial distribution of economic activities: geographical discrepancies are 
not amplified and eventually disappear. Instead, we build on some recent developments of economic geography that study the impact of frictions to goods and factors mobility on the location of imperfectly competitive industries in the presence of increasing returns to scale (Fujita et al., 1999; Fujita and Thisse, 1996; Ottaviano and Puga, 1998). In particular, we rely on Krugman's (1991) classical model as modified by Ottaviano and Thisse (1998) who propose the adoption of an alternative demand system that, contrary to the original one, is amenable to analytical solutions and proper welfare comparisons. ${ }^{2}$

In Krugman's set-up there are two regions, two sectors and two specific factors. The traditional sector employs unskilled workers to produce a homogeneous good which is perfectly competitive and freely traded. The modern sector employs skilled workers to supply a differentiated good which is monopolistically competitive and costly traded. In accordance with the empirical evidence (see, e.g., Shields and Shields, 1989), unskilled workers are assumed to be much less mobile than skilled ones. One may wonder if the assumption of mobility of the skilled is reasonable in an area where linguistic and cultural barriers have often be considered as a major impediments to mobility. Some transformations are taking place within the EU that make this assumption more plausible that it might seem at first sight. First, English becomes the lingua franca of the business and scientific communities as well as that of most international institutions. Second, the construction of a High Speed Rail connecting the main conurbations of the Union (such as the TGV) seems to enhance the mobility of the skilled. Although it is premature to conclude, it is worth mentioning that, since the Channel Tunnel has been built, the City of London has already attracted a fairly large number of French financial operators who used to work in Paris. To be sure, services account for a substantial share of the modern sector and many services are produced where they are consumed. However, it is reasonable to expect high-level services' workers to be mobile, thus making likely their agglomeration in a few large metropolitan regions.

Having said that, the core-periphery model reveals that for low transport costs (broadly defined to encompass any impediment to trade) skilled labor mobility causes the modern sector to cluster in one region because the posi-

\footnotetext{
${ }^{2}$ Most of the models surveyed in Fujita et al. (1999) and Ottaviano and Puga (1998) are based on a nested-CES demand system which is not really suited to address the question of the efficiency of economic agglomeration because the marginal utility of the numéraire is not constant but differs between agents with different endowments.
} 
tive aggregate demand effect of skilled workers' immigration on profits more than offsets the negative competition effect of modern firms' inflow. Though path-breaking, Krugman's seminal contribution falls short of providing any welfare evaluation of the implied pattern of regional specialization. This is our first aim: we want to determine whether or not the spatial concentration of the modern sector is socially desirable and to assess its pros and cons by disentangling the various external effects which cause its emergence.

Previewing our results, we begin by pointing out that the market outcome is socially desirable when transport costs are either high or low. While in the former case activities are dispersed, in the latter they are agglomerated. By contrast, for intermediate values of these costs, the mark1et leads to the agglomeration of the modern sector whereas it is socially optimal to keep it geographically dispersed. In this case, in which the equity-efficiency trade-off disappears, we recognize the scenario envisioned by the European Commission. This is an interesting finding in that low transport costs may be viewed as corresponding to shipping costs between small-sized regions, whereas large costs would instead be the counterpart of trade costs between large trading blocks. Intermediate values would therefore correspond to shipping costs between regions belonging to medium-sized areas such as the EU. This interpretation would suggest that there could well be too much geographical concentration within the EU after the effects of the Single Market were completed (Martin, 1999). If so, our finding would provide an efficiency-grounded case for an active regional policy at the level of the European Union.

Once we have established the suboptimality of the market-delivered economic landscape, we can move on towards our second objective, that is to understand whether the actual mechanics of European policy making has any chance of delivering the economically efficient outcome. In principle, the effectiveness of the Commission is hampered by at least two crucial problems. First, the costs of an inefficient economic landscape are likely to be unevenly distributed among different interest groups so that any active regional intervention is bound to generate a conflict between opposite interests (Mazey and Mitchell, 1993). Second, effective intervention requires enormous information-gathering capabilities that, due its relatively small bureaucracy, the Commission is unlikely to possess (Gorges, 1996). This second aspect appears even more severe if one considers that, even though sometimes (under the 'assent' and 'cooperation' procedures) it has to ask for the opinion of the European Parliament, 
the Commission is an unelected body and thus it receives no direct feed-back from any electorate (Mazey and Richardson, 1993). Both problems have led the Commission to adopt the role of an intermediator between conflicting interests that are thus urged to get organized as pressure groups in order to improve the transmission of information about their collective needs (Gorges, 1996). In 1993 as many as 525 interests groups were officially recognized and regularly consulted by the Commission (Mazey and Richardson, 1993) while the current estimate of people involved in interest representation in Brussels is close to 13,000 (The Economist, 1998).

Our model lends itself quite naturally to studying the political economy of the distributive effects generated by the formation and the development of a core region. Specifically, it can be used to show that the population of unskilled workers is always negatively affected by the emergence of a coreperiphery structure because their access to the output of the modern sector becomes too costly. In other words, members of the traditional sector oppose the deepening of the European unification process. By contrast, the skilled workers may be either better off or worse off when they are agglomerated, because each mover does not internalize the external effects that her move imposes on all other skilled. More precisely, when the number of skilled workers is sufficiently low (large), moving toward the large region may be individually rational (irrational) but collectively irrational (rational) from the mobile workers' point of view. In this case, both groups of workers are against the deepening of the unification process. However, when the population of skilled workers is large enough, the two groups have conflicting interests because the skilled now gain from being clustered within the same region. This conflict gives rise to the emergence of competing interest groups.

Anticipating our results, by building on the literature on informational lobbying (Potters and van Linden, 1992; Austen-Smith, 1993) and on the theory of menu auctions (Bernheim and Whinston, 1986), we are able to show that, first, lobbying by conflicting pressure groups for or against the mobility of the skilled workers allows the Commission to implement the second best optimum economic landscape and, second, the actual coalitions of interests that are formed are immaterial for the attainment of efficiency since their composition has only redistributive implications. These results holds if lobbying is 'competitive' in the sense that all interests have free access to the Commission, all face the same costs of collective action and the Commission simply 
acts as a mediating organization ('honest broker'). This provides a useful benchmark for political conduct. It implies that, for implementing efficient regional policies, the Commission has to lend a candid hear to all interests as well as to promote their participation to the lobbying process with particular emphasis on those interests that, because they are diffuse, face larger costs of collective action (Olson, 1980). Under this respect, our results provide some rationale to the extension of qualified majority voting by the SEA, which in 1992 substituted the national veto power with qualified majority voting on measures necessary to complete the internal market and to new policy sectors (R\&D, health and safety, environment). This has increased "the appeal of, and the need for, rapid transnational interest definition, aggregation, and coordination" (Gorges, 1996), thus favoring the coalition of diffuse Euro-wide interests.

The remainder of the paper is organized as follows. The next section presents a simple model yielding a core-periphery structure when transport costs are low. Section 3 identifies the conditions under which the geographical agglomeration of skilled workers is a market equilibrium, the first best optimum or a second best optimum in which firms must break even. Section 4 deals with the welfare of skilled and unskilled workers. Section 5 discusses the desirability of agglomeration from the social point of view as well as from the standpoint of each group of workers. Section 6 analyzes the lobbying game involving the groups of skilled and unskilled workers. Section 7 concludes.

\section{A simple model of agglomeration}

Consider a spatial economy formed by two sectors, $M$ and $T$, two regions, $H$ and $F$, and two production factors, $L$ and $A$, the first being (perfectly) mobile and the second immobile. Although other interpretations are possible, it is convenient to think of the mobile factor as skilled workers and the immobile one as unskilled workers. Indeed, empirical studies suggest that the skilled are more mobile than the unskilled (e.g. Shields and Shields, 1989, pp. 279, 285 and 287), maybe because education generates human capital which is easily transferable to another region and eases the search for job, residency and a social environment to live in. The modern sector $M$ exhibits scale economies 
and operates under monopolistic competition. ${ }^{3}$ The corresponding output is horizontally differentiated. There is a continuum of firms whose number $N$ is determined under free entry. Each firm produces a single variety by means of a fixed amount $\phi$ of skilled labor $L$. The traditional sector $T$ produces a homogeneous good under constant returns to scale, using unskilled labor $A$ as the only input: one unit of $A$ is required to produce one unit of output. This good is freely traded and is chosen as the numéraire. The varieties of the modern sector are traded at a cost of $\tau$ units of the numéraire per unit shipped between the two regions. The economy is endowed with $A$ units of unskilled who are equally split between regions, and with $L$ units of skilled whose fraction $0 \leq \lambda \leq 1$ is located in region $H$.

Preferences are identical across individuals and described by the following quasi-linear indirect utility function which is symmetric in all varieties:

$$
\begin{gathered}
V(y ; p(i), i \in[0, N])=-a \int_{0}^{N} p(i) d i+\frac{b+c N}{2} \int_{0}^{N}[p(i)]^{2} d i \\
-c \int_{0}^{N} \int_{0}^{N} p(i) p(j) d i d j+y+\bar{q}_{0}
\end{gathered}
$$

where $p(i)$ is the price of variety $i \in[0, N], y$ the consumer labor income, and $\bar{q}_{0}$ her initial endowment in the numéraire. The parameters in (1) are such that $a>0$ and $b \geq c>0$. In this expression, $a$ is a measure of the size of the market (since it expresses the intensity of preferences for the differentiated product), whereas a large value for $b$ means that the representative consumer is biased toward a dispersed consumption of varieties, thus reflecting a love for variety. ${ }^{4}$ For a given value of $b$, the parameter $c$ expresses the substitutability between varieties: the higher $c$, the closer substitutes the varieties. Finally, we assume that the initial endowment $\bar{q}_{0}$ in the numéraire is large enough for the consumption of the numéraire to be strictly positive at the market equilibrium and optimal solutions. Throughout the paper, we will encounter several conditions involving the various parameters of the model. In particular, we will assume that the least demanding condition regarding trade costs and

\footnotetext{
${ }^{3}$ Unlike most of the existing literature on economic geography, we do not use here the Dixit-Stiglitz model but another one whose details may be found in Ottaviano and Thisse (1999).

${ }^{4}$ The direct utility behind (1) is the standard quadratic utility yielding linear demand functions (see Ottaviano and Thisse, 1999, for more details).
} 
preference parameters, that is,

$$
\tau \leq a / b
$$

is always satisfied. This condition is necessary for any single firm to find it profitable to sell in the foreign market, regardless of whom pays for the trade costs.

Labor market clearing implies that the number $n_{H}$ of firms belonging to the modern sector and located in region $H$ is equal to:

$$
n_{H}=\lambda L / \phi
$$

so that the number of firms in $F$ is

$$
n_{F}=(1-\lambda) L / \phi .
$$

Consequently, the total number of firms (varieties) in the economy is fixed and equal to $N=L / \phi$.

Entry and exit are free so that profits are zero in equilibrium. Hence, (3) and (4) imply that any change in the population of workers located in one region must be accompanied by a corresponding change in the mass of firms. By (3) and (4), the demand and supply of workers in each region are equal. As a result, the corresponding equilibrium wages are determined by a bidding process among firms which ends when no firm can earn a strictly positive profit at the equilibrium market prices.

By assumption, firms compete in segmented markets. Indeed, even within a unified economic area, there are many good reasons to believe that firms will succeed to segment markets (Horn and Shy, 1996). Even today, empirical work such as Head and Mayer (1998) shows that the EU is still very segmented. In the sequel, we focus on region $H$. Things pertaining to region $F$ can be derived by symmetry. Using the assumption of symmetry between varieties and Roy's identity, individual demands for a representative firm in $H$ are given by:

$$
q_{H H}=a-(b+c N) p_{H H}+c P_{H}
$$

and

$$
q_{H F}=a-(b+c N) p_{H F}+c P_{F}
$$

where

$$
P_{H} \equiv n_{H} p_{H H}+n_{F} p_{F H}
$$




$$
P_{F} \equiv n_{H} p_{H F}+n_{F} p_{F F}
$$

Clearly, $P_{H} / N$ and $P_{F} / N$ can be interpreted as the price indexes prevailing in region $H$ and $F$.

A representative firm in $H$ maximizes its profits defined by:

$$
\begin{aligned}
\Pi_{H}= & p_{H H}\left[a-(b+c N) p_{H H}+c P_{H}\right][A / 2+\lambda L]+ \\
& \left(p_{H F}-\tau\right)\left[a-(b+c N) p_{H F}+c P_{F}\right][A / 2+(1-\lambda) L]-\phi w_{H}
\end{aligned}
$$

where $A / 2$ stands for the unskilled's population in each region.

Market prices are obtained by maximizing profits while wages are determined as described above by equating the resulting profits to zero. Since we have a continuum of firms, each one is negligible in the sense that its action has no impact on the market. Hence, when choosing its prices, a firm in $H$ accurately neglects the impact of its decision over the two price indices $P_{H}$ and $P_{F}$. In addition, because firms sell differentiated varieties, each one has some monopoly power in that it faces a demand function with finite elasticity. On the other hand, since the price index enters the demand function as an additive term (see (5) and (6)), a firm must account for the distribution of the firms' prices through some aggregate statistics, given here by the average market price, in order to find its equilibrium price. As a consequence, our market solution is given by a Nash equilibrium with a continuum of players in which prices are interdependent: each firm neglects its impact on the market but is aware that the market as a whole has a non-negligible impact on its behavior.

Since profit functions are concave in own price, solving the first order conditions for profit maximization with respect to prices yields the equilibrium prices:

$$
\begin{gathered}
p_{H H}=\frac{1}{2} \frac{2 a+\tau c N(1-\lambda)}{2 b+c N} \\
p_{F F}=\frac{1}{2} \frac{2 a+\tau c N \lambda}{2 b+c N} \\
p_{H F}=p_{F F}+\frac{\tau}{2} \\
p_{F H}=p_{H H}+\frac{\tau}{2}
\end{gathered}
$$

Thus, the equilibrium prices under monopolistic competition depend on the total number of active firms as well as on their distribution between the two regions. In particular, using (2) we observe that more firms in the economy 
leads to lower market prices for the same spatial distribution $(\lambda, 1-\lambda)$ because there is more competition in each regional market. Similarly, both the prices charged by local and foreign firms fall when the mass of local firms increases because competition is fiercer. Equilibrium prices also rise when the size of the local market, evaluated by $a$, gets larger or when the degree of product differentiation, inversely measured by $c$, increases provided that (2) holds. All these results agree with what is known in industrial organization and spatial pricing theory (Tirole, 1988, ch.7).

Substracting $\tau$ from (9) and (10), we see that firms' prices net of trade costs are positive regardless of the workers' distribution if and only if

$$
\tau<\tau_{\text {trade }} \equiv \frac{2 a \phi}{2 b \phi+c L}
$$

The same condition must hold for consumers in $F(H)$ to buy from firms in $H$ $(F)$, i.e. for the demand (6) evaluated at the prices (7) and (8) to be positive for all $\lambda$. Clearly (11) is more restrictive than (2). From now on, condition (11) is assumed to hold. Consequently, we consider a setting in which there is a priori intra-industry trade and reciprocal dumping.

Finally, local sales rise with $\tau$ because of the higher protection enjoyed by the local firms but exports fall for the same reason. It is easy to check that the equilibrium operating profits earned by a firm established in $H$ on each separated market are as follows:

$$
\Pi_{H H}=(b+c N) p_{H H}^{2}(A / 2+\lambda N \phi)
$$

where $\Pi_{H H}$ denotes the profits earned in $H$ while the profits made from selling in $F$ are

$$
\Pi_{H F}=(b+c N)\left(p_{H F}-\tau\right)^{2}[A / 2+(1-\lambda) N \phi]
$$

Increasing $\lambda$ has two opposite effects on $\Pi_{H H}$. First, the equilibrium price (7) falls as well as the quantity of each variety bought by each consumer living in region $H$. However, the total population of consumers residing in this region is now larger so that the profits made by a firm located in $H$ on local sales may increase. What is at work here is a positive demand effect due to the increase in the local population that may compensate firms for both the adverse price effect and the reduction in individual demand due to the presence of a larger number of local varieties. 
The individual consumer surplus $S_{H}$ in region $H$ associated with the equilibrium prices (7) and (10) is then as follows (a symmetric expression holds in region $F$ ):

$$
\begin{aligned}
S_{H}= & -a\left[\lambda p_{H H}+(1-\lambda) p_{F H}\right] N+\frac{b+c N}{2}\left[\lambda p_{H H}^{2}+(1-\lambda) p_{F H}^{2}\right] N \\
& -c\left[\lambda p_{H H}+(1-\lambda) p_{F H}\right]^{2} N^{2}
\end{aligned}
$$

\section{Equilibrium and optimum spatial configurations}

\subsection{The market outcome}

We now ask whether for a given spatial distribution of skilled workers, $(\lambda, 1-$ $\lambda)$, there is an incentive for them to migrate and, if so, what direction the flow of migrants will take. Following the tradition of economic geography, we assume that skilled workers care only about their current utility levels. ${ }^{5}$ Accordingly, if they observe that a location offers a higher indirect utility than the other, they want to move to that location. When moving, workers anticipate that 'some' firms will follow them. More precisely, the number of firms that relocate must be such that (3) and (4) remain valid for the new distribution of workers; wages are adjusted in each region for each firm to earn zero profits everywhere. Consequently, the driving force in the migration process is workers' indirect utility differential between $H$ and $F$, denoted

$$
\begin{aligned}
\Delta V & \equiv V_{H}-V_{F}=S_{H}-S_{F}+w_{H}-w_{F} \\
& =S_{H}-S_{F}+\left(\Pi_{H H}+\Pi_{H F}\right) / \phi-\left(\Pi_{F F}+\Pi_{F H}\right) / \phi
\end{aligned}
$$

so that the equation of motion is:

$$
\dot{\lambda} \equiv d \lambda / d t=\Delta V \cdot \lambda \cdot(1-\lambda)
$$

If $\Delta V$ is positive, the skilled will move from $F$ to $H$; if it is negative, they will go in opposite direction.

A spatial equilibrium arises when $\dot{\lambda}=0$. This happens at $\lambda \in(0,1)$ when $\Delta V(\lambda)=0$ in which case we have a dispersed configuration. Motion also

\footnotetext{
${ }^{5}$ Notice, however, that this approach leads to a fairly good approximation of forwardlooking behavior whenever skilled workers discount the future heavily and/or their migration process is very slow (Ottaviano, 1996).
} 
stops at endpoints $\lambda=0$ when $\Delta V(0) \leq 0$ or at $\lambda=1$ when $\Delta V(1) \geq 0$ in which case we have an agglomerated configuration. Therefore, the agglomerated configuration is always stable when it is an equilibrium while the dispersed configuration is stable when the slope of $\Delta V(\lambda)$ is negative.

The following comments are in order about the dynamics of migration of both consumers and firms. The immobility of the unskilled is a centrifugal force, at least as long as there is trade in the differentiated product between the two regions. The centripetal force is more elaborated. If an increasing number of firms are located in region $H$, there are two effects at work. First, more varieties are locally available (variety effect). Second, (7) and (10) imply that the equilibrium prices of all varieties sold in $H$ are lower (competition effect). Both effects generate a higher indirect utility. This in turn induces some consumers to migrate toward this region. The resulting increase in the number of consumers creates a larger demand for the output of the modern sector in region $H$ (demand effect), which therefore leads more firms to locate there.

The indirect utility differential is obtained by plugging the equilibrium prices (7)-(10) and, using (3) and (4), the equilibrium wages for the workers into (1):

$$
\begin{aligned}
\Delta V= & \frac{\tau(b \phi+c L) L}{4 \phi^{2}(2 b \phi+c L)^{2}}(2 \lambda-1)\{12 a \phi(b \phi+c L) \\
& \left.-\tau\left[c^{2} A L+4 b c \phi L+2 b c \phi A+6 b^{2} \phi^{2}-c^{2} L^{2}\right]\right\}
\end{aligned}
$$

It follows immediately from this expression that $\lambda=1 / 2$ is always a spatial equilibrium. The stability analysis of this equilibrium is easy to perform. Since (12) is linear in $\lambda$, the critical value of $\tau$ below which symmetry is no longer stable and the value below which agglomeration is stable are identical. For $\lambda \neq 1 / 2$, the indirect utility differential has always the same sign as $2 \lambda-1$ if and only if the curly bracketed term is positive, a condition which holds if and only if:

$$
\tau<\tau^{M} \equiv \frac{12 a \phi(b \phi+c L)}{c^{2} A L+4 b c \phi L+2 b c \phi A+6 b^{2} \phi^{2}-c^{2} L^{2}}
$$

For the analysis to be meaningful, we need $0<\tau^{M}<\tau_{\text {trade }}$. Otherwise trade would always imply agglomeration. Indeed, $\Delta V$ is then a convex function of $\tau$ which reaches its minimum at a negative value of $\tau$ and equals zero at 
$\tau=0$, thus implying that the coefficient of $2 \lambda-1$ in (12) is always positive for all admissible values of $\tau$. Competition among local firms is very weak and the demand effect is always strong enough to yield agglomeration.

The inequality $0<\tau^{M}<\tau_{\text {trade }}$ holds if, and only if,

$$
A>\frac{7 c L(c L+2 b \phi)+6 b^{2} \phi^{2}}{c(2 b \phi+c L)}
$$

which is satisfied when varieties are not too differentiated ( $c$ large), increasing returns in the modern sector are not too large ( $\phi$ small), and/or the population of unskilled in the global economy is sufficiently large ( $A$ large). We will assume throughout the rest of the paper that (14) holds.

When $\tau<\tau^{M}$, the symmetric spatial equilibrium is unstable and workers agglomerate in region $H(F)$ provided that the initial fraction of skilled workers residing in this region exceeds $1 / 2$. In other words, insofar as (14) is satisfied, agglomeration arises when trade is not too costly ( $\tau$ small), varieties are very differentiated ( $c$ small) and/or when increasing returns in the modern sector are strong ( $\phi$ large). When this is not the case, all activities are dispersed because the symmetric configuration is the only stable equilibrium.

Proposition 1 Assume that $\tau<\tau_{\text {trade }}$ and that (14) holds. Then, if $\tau>\tau^{M}$ the symmetric configuration is the only stable equilibrium with trade; if $\tau<\tau^{M}$ there are two stable equilibria corresponding to the agglomerated configurations with trade; if $\tau=\tau^{M}$ there is a continuum of equilibria.

The nature of trade varies with the type of configuration emerging in equilibrium. In the dispersed configuration, there is only intra-industry trade in the modern sector; in the agglomerated equilibrium, trade is only interindustry: the core region only imports the output of the traditional sector from the peripheral region which only imports the output of the modern sector from the core region.

\subsection{A geometrical proof}

The best way to convey the economic intuition behind this result is probably to make use of a graphical analysis. Figure 1 depicts the aggregate inverse 
demand in region $H$ for a typical local variety after choosing, for simplicity, the units of $L$ so that $b+c N=1$ :

$$
p_{H H}=a+c P_{H}\left(n_{H}, \tau\right)-\frac{Q_{H H}}{A / 2+\phi n_{H}}
$$

where $Q_{H H}$ is the aggregate local demand of a firm located in $H$ and, because $p_{F H}>p_{H H}$ and the total number of firms is fixed by skilled labor market clearing, the price index $P_{H}$ is a decreasing function of $n_{H}$ at a rate which increases with $\tau$ :

$$
\frac{\partial P_{H}\left(n_{H}, \tau\right)}{\partial n_{H}}<0,\left|\frac{\partial^{2} P_{H}\left(n_{H}, \tau\right)}{\partial n_{H} \partial \tau}\right|>0
$$

The horizontal and vertical intercepts of (15) are respectively $\left[a+c P_{H}\left(n_{H}, \tau\right)\right]$ times $\left[A / 2+\phi n_{H}\right]$ and $\left[a+c P_{H}\left(n_{H}, \tau\right)\right]$. The equilibrium values of $Q_{H H}$ and $p_{H H}$ are shown as $Q_{H H}^{\prime}$ and $p_{H H}^{\prime}$. They are found by setting marginal revenue equal to marginal cost. The operating profits are shown by the shaded rectangle and accrue to the skilled workers while, as usual, the above triangle represents the consumer surplus enjoyed by both skilled and unskilled workers.

The picture is a powerful learning device to understand the forces at work in the model. To see why, start from an initial situation where regions are identical $\left(n_{H}=n_{F}\right)$. Suppose that some firms move from the foreign to the home region so that $n_{H}$ rises and $n_{F}$ falls. For these firms to want to stay in the home region, operating profits have to increase. Indeed, were this not the case, the firms would rather go back to the foreign region.

Consider Figure 1. An increase in $n_{H}$ has two opposite effects on operating profits. First, as new firms enter the home region, the price index $P_{H}\left(n_{H}, \tau\right)$ decreases. Ceteris paribus, this would shift the inverse demand (15) toward the origin of the axes and operating profits would shrink. This effect is due to increased competition in the home market and stems from the fact that fewer firms now face trade costs when supplying the home market. But this negative competition effect is not the only effect. For some firms to move to the home region, some skilled workers have to follow $\left(n_{H}=\lambda L / \phi\right)$. This means that, as $n_{H}$ increases, also $\lambda$ goes up so that the market of the home region expands. Ceteris paribus, the horizontal intercept of the inverse demand would move away from the origin and profits would expand. This is a positive demand effect which is induced by the linkage between the locations of firms and skilled workers' expenditures. 
Since the two effects oppose each other, the net result is a priori ambiguous. But we can say more than that. In particular, we can assess which effect prevails depending on parameter values. Start with the competition effect that goes through $\left[a+c P_{H}\left(n_{H}, \tau\right)\right]$. This effect is strong if $c$ is large, i.e. if varieties are good substitutes. It is also strong if $\left|\partial P_{H}\left(n_{H}, \tau\right) / \partial n_{H}\right|$ is large. As shown in (16), this happens if $\tau$ is large, because, when obstacles to trade are high, competition from the other region is weak and home firms care a lot about their competitors being close rather than distant. As to the demand effect, it will be strong if $\phi$ is large because each new firm brings along many skilled workers, and if $A$ is small because immigrants have a large impact on the local market size.

We can therefore conclude that the demand effect dominates the competition effect, when goods are bad substitutes ( $c$ small), increasing returns are intense ( $\phi$ large), the unskilled workers are unimportant ( $A$ small) and trade costs are low ( $\tau$ small). Under such circumstances, the entry of new firms in one region would raise the operating profits of all firms. Higher profits would attract more firms, generating circular causation among firms location decision. Agglomeration would then be sustainable as a spatial equilibrium. ${ }^{6}$

\subsection{Efficiency: the first best outcome}

We assume that the planner is able (i) to assign any number of skilled workers (or, equivalently, of firms belonging to the modern sector) to a specific region and (ii) to use lump sum transfers from all workers to pay for the loss firms incur while pricing at marginal cost. The skilled have to work in order to have access to the output of the modern sector. The planner chooses $\lambda$ in order to maximize the following social welfare function (recall that individual utilities are quasi-linear):

$$
W=\frac{A}{2} S_{H}+\lambda L\left(S_{H}+w_{H}\right)+\frac{A}{2} S_{F}+(1-\lambda) L\left(S_{F}+w_{F}\right)
$$

\footnotetext{
${ }^{6}$ More rigorously, this argument establishes a sufficient condition for agglomeration. Because skilled firms and workers have to move together, in order to obtain a necessary condition, one should also consider the impact of firms' delocation on consumer surplus. Indeed, it is perfectly conceivable that the variety effect may sustain agglomeration even when the demand effect is dominated by the competition effect.
} 
which, up to an additive constant, is simply the sum of all workers' indirect utilities and where all prices have been set equal to marginal cost:

$$
p_{H H}=p_{F F}=0 \quad \text { and } \quad p_{H F}=p_{F H}=\tau
$$

Hence (17) becomes:

$$
\begin{gathered}
W=-\frac{\tau L}{4 \phi^{2}}[4 L(-2 a \phi+ \\
-A b \phi+\tau c A) \lambda^{2}-4 L(-2 a \phi+\tau b \phi+\tau c A) \lambda \\
-A(2 a \phi-\tau b \phi+\tau c L)]
\end{gathered}
$$

which is strictly concave in $\lambda$ if the coefficient of $\lambda^{2}$ (namely $-2 a \phi+\tau b \phi+\tau c A$ ) is positive and strictly convex if this coefficient is negative. Furthermore, since the coefficient of $\lambda^{2}$ and of $\lambda$ are the same (up to their sign), this expression has always an interior extremum at $\lambda=1 / 2$. As a result, the optimal choice of the planner is determined by the sign of the coefficient of $\lambda^{2}$ in (18). The critical value of $\tau$ arises when the sign of the coefficient of $\lambda^{2}$ changes, and it is given by

$$
\tau^{O} \equiv \frac{a \phi}{b \phi+c A}
$$

Hence we have:

Proposition 2 If $\tau>\tau^{O}$, then the symmetric configuration is the first best optimum; if $\tau<\tau^{O}$ any agglomerated configurations is an optimum; if $\tau=\tau^{O}$ there is a continuum of optima.

As expected, it is socially desirable to agglomerate the modern sector into a single region once trade costs are low, increasing returns in the modern sector are strong enough and/or the output of the modern sector is differentiated enough.

\subsection{Efficiency: the second best outcome}

We now assume that lump sum transfers are not available to the planner who is only able to assign locations to the skilled workers. For example, in China and Russia, rural-urban migrations were restricted through a system 
of permits while, in India, industrial firms were prohibited from locating new plants in or close to large cities (World Bank, 1999).

In such a context, the social welfare function is still given by (17) but it is evaluated at the equilibrium prices (7)-(10):

$$
W_{S}=-\frac{L(b \phi+c L)}{8 \phi^{2}(2 b \phi+c L)^{2}}\left(K_{1} \lambda^{2}+K_{2} \lambda+K_{3}\right)
$$

where $K_{1} \equiv L \tau\left[\left(7 c^{2} A L+12 b c \phi L+12 b c \phi A+24 b^{2} \phi^{2}-c^{2} L^{2}\right) \tau-32 a c \phi L-\right.$ $\left.48 a b \phi^{2}\right], K_{2} \equiv-K_{1}$, and $K_{3} \equiv 2\left(6 a b \phi^{2} \tau A+2 a^{2} \phi^{2} A+2 a^{2} \phi^{2} L+4 a c \phi \tau A L\right.$ $\left.+c^{2} \tau^{2} A L^{2}-3 b^{2} \phi^{2} \tau^{2} A\right)$. Since $K_{2} \equiv-K_{1}, \lambda=1 / 2$ is always a solution.

The choice of the planner is similar to that described in the first best case except that the critical value $\tau$ of is now given by the following expression:

$$
\tau^{S} \equiv \frac{16 a \phi(3 b \phi+2 c L)}{7 c^{2} A L+12 b c \phi L+12 b c \phi A+24 b^{2} \phi^{2}-c^{2} L^{2}}
$$

It is readily verified that $\tau^{M}>0$ implies $\tau^{S}>0$. Hence we have:

Proposition 3 Assume that (14) holds. If $\tau>\tau^{S}$, then the symmetric configuration is the second best optimum; if $\tau<\tau^{S}$ any agglomerated configuration is a second best optimum; if $\tau=\tau^{S}$ there is a continuum of second best optima.

\section{Welfare for the skilled and unskilled workers}

Consider first the welfare of the skilled which is defined, up to an additive constant, by:

$$
W_{L}=\lambda L\left(S_{H}+w_{H}\right)+(1-\lambda) L\left(S_{F}+w_{F}\right)
$$

evaluated at the equilibrium prices (7)-(10), that is:

$$
W_{L}=-\frac{b \phi+c L}{8 \phi^{2}(2 b \phi+c L)^{2}}\left(K_{1}^{L} \lambda^{2}+K_{2}^{L} \lambda+K_{3}^{L}\right)
$$

where $K_{1}^{L} \equiv L \tau\left[\left(2 c^{2} A L+12 b c \phi L+8 b c \phi A+24 b^{2} \phi^{2}-c^{2} L^{2}\right) \tau-32 a c \phi L-48 a b \phi^{2}\right]$, $K_{2}^{L} \equiv K_{1}^{L}$, and $K_{3}^{L} \equiv 4 \phi^{2}\left(2 a b \tau A+a^{2} L-b^{2} \tau^{2} A-2 a^{2} A\right)$. Since $K_{2}^{L} \equiv K_{1}^{L}$, 
$\lambda=1 / 2$ is always a solution. The critical value of $\tau$ for which the whole group of skilled prefer agglomeration to any other distribution may be obtained as in the foregoing:

$$
\tau^{L} \equiv \frac{16 a \phi(3 b \phi+2 c L)}{2 c^{2} A L+12 b c \phi L+8 b c \phi A+24 b^{2} \phi^{2}-c^{2} L^{2}}
$$

which is clearly strictly larger than $\tau^{S}$.

We now come to the welfare of the unskilled which, up to an additive constant, is equal to:

$$
W_{A}=\frac{A}{2}\left(S_{H}+S_{F}\right)
$$

evaluated again at the equilibrium prices (7)-(10):

$$
W_{A}=-\frac{L(b \phi+c L)}{8 \phi^{2}(2 b \phi+c L)^{2}}\left(K_{1}^{\prime \prime} \lambda^{2}+K_{2}^{\prime \prime} \lambda+K_{3}^{\prime \prime}\right)
$$

where $K_{1}^{\prime \prime} \equiv 2 c A L \tau^{2}(5 c L+4 b \phi), K_{2}^{\prime \prime} \equiv K_{1}^{\prime \prime}$, and $K_{3}^{\prime \prime} \equiv 2 A\left(2 a b \phi^{2} \tau+6 a^{2} \phi^{2}+\right.$ $\left.4 a c \phi \tau L+c^{2} \tau^{2} L^{2}-b^{2} \phi^{2} \tau^{2}\right)$. Since $K_{1}^{\prime \prime}$ is always strictly positive, the optimal choice for the unskilled workers is always the same in that they prefer the dispersed configuration to the agglomerated one.

To sum-up, we have:

Proposition 4 If $\tau>\tau^{L}$, then the skilled workers prefer the symmetric configuration to any other; if $\tau<\tau^{L}$ they prefer the agglomerated configuration to any other; if $\tau=\tau^{L}$ they are indifferent. Regardless of the value of $\tau$, the unskilled prefer the dispersed configuration to any other.

\section{Is agglomeration desirable? And for whom?}

As seen in Section 3.1, a deepening in the integration of different economies is likely to lead to the emergence of a core region accommodating the entire modern sector. We now wish to determine (i) whether or not such an agglomeration is socially optimal and (ii) which groups of workers are the winners or losers when agglomeration arises as a market equilibrium. 
There are several distortions and external effects at work in the present model which are likely to lead to significant discrepancy between equilibrium and optimum. Besides the standard distortion due to the fact that firms do not price at marginal cost, there are pecuniary externalities and, since our economy is imperfectly competitive, they matter for the level of welfare. In particular, skilled workers impose a pecuniary externality on the workers of the traditional sector. Their move affects the intensity of local competition as well as the amount spent by the unskilled on trade costs. As seen in Proposition 4, the unskilled are always worse off when the skilled agglomerate. In addition, when skilled workers move from one region to the other, they do not account either for the impact of their migration on the other skilled. Such move affects not only the intensity of competition but also the level of demand inside each region, and, therefore, their wages. Note, however, that there is no over- or under-entry effect. Indeed, the number $N$ of firms is the same in equilibrium and at the optimum since it is determined by the technology and equal to $L / \phi$.

In order to study the impact of these various effects, we need to rank the different threshold values for $\tau$ obtained in the previous sections.

\subsection{Equilibrium vs optimum}

Some simple calculations show that $\tau^{O}<\tau^{S}<\tau^{M}$ when (14) holds. These inequalities reveal several important things. First, $\tau^{O}<\tau^{S}$, namely agglomeration is desirable for higher values of the transport cost in the second best. This is because the individual demand elasticity is much lower in the first best (marginal cost pricing) than in the second best (Nash equilibrium pricing), so that regional price indices are less sensitive to a decrease in $\tau$. The fall in transport costs must be sufficiently large to make the agglomeration of the mobile workers socially desirable.

Second, we also have $\tau^{S}<\tau^{M}$. This is because skilled workers do not internalize the negative external effects they impose on the unskilled who always prefer dispersion as shown by Proposition 4. Hence, even though the skilled have incentives to move, these incentives do not reflect the social value of their move.

This discrepancy is even stronger when we compare the first best outcome and the market equilibrium because we have just seen that marginal cost pricing is more favorable to dispersion. As a result, the market yields 
an agglomerated configuration for a whole range $\left(\tau^{O}<\tau<\tau^{M}\right)$ of trade cost values for which it is socially desirable to have a dispersed pattern of activities. We can also show that

$$
\tau^{M}-\tau^{O}>\frac{a \phi}{b \phi+c A}
$$

so that the size of the range for which equilibrium and optimum differ is bounded from below by a value which increases with increasing returns and/or the degree of product differentiation in the modern sector. On the other hand, when the size of the traditional sector rises this bound decreases.

Accordingly, when transport costs are low $\left(\tau<\tau^{O}\right)$ or high $\left(\tau>\tau^{M}\right)$ the market yields the optimum so that no regional policy is required from the efficiency point of view, although equity considerations might still justify such a policy when agglomeration arises. On the contrary, for intermediate values of transport $\operatorname{costs}\left(\tau^{O}<\tau<\tau^{M}\right)$, the market provides excessive agglomeration, thus justifying the need for an active regional policy in order to foster the dispersion of the modern sector from both the efficiency and equity grounds.

The first best optimum requires the implementation of lump-sum transfers. If such transfers are not feasible while the planner is still able to control the locations of the skilled workers, it remains true that, for some values of the trade $\operatorname{costs}\left(\tau^{S}<\tau<\tau^{M}\right)$, the market outcome is agglomeration whereas the second best optimum involves dispersion. Nevertheless, the discrepancy is less severe than with the first best outcome since the gap $\tau^{M}-\tau^{S}$ is narrower than $\tau^{M}-\tau^{O}$. Still, in both cases, we have an illustration of what was claimed by the European Commission in the quotation made in the introduction.

We can again use the geometrical analysis of 3.2 to understand the bias of the decentralized outcome. Starting again from perfect symmetry between regions $\left(n_{H}=n_{F}, Q_{H H}^{\prime}=Q_{F F}^{\prime}\right.$, and $\left.p_{H H}^{\prime}=p_{F F}^{\prime}\right)$, Figure 2 shows what would happen to the local inverse demands in the two regions were the locations of firms to change while holding their prices and the price indexes constant, that is, while isolating the model from the competition effect. The linearity of demand implies that, in terms of both operating profits and consumer surpluses, one region gains what the other loses. This is shown by the identity of the areas of the two shaded rectangles and of the two corresponding triangles above them which stems from the fact that the horizontal intercepts of the modified regional demands are symmetric around the initial one implying $Q_{H H}^{\prime}-Q_{1}=Q_{2}-Q_{H H}^{\prime}$. Therefore, the market size effect is 
immaterial from an efficiency viewpoint. The crucial source of distortion is then the neglect of the competition effect by firms. Since they underestimate their positive (negative) impact on the intensity of competition in the region of destination (origin) and the competition effect is stronger the larger the transport costs, they tend to agglomerate below a threshold value of $\tau$ which is larger than the efficient ones. ${ }^{7}$

\subsection{Agglomeration and the welfare of skilled and unskilled}

We now want to determine to what extent the cooperative behavior of skilled workers in the migration process affects the well-being of the two groups of workers evaluated at the equilibrium prices. In this case, the skilled are assumed to act together in order to internalize all the effects that an individual mover has on the other skilled. However, they still disregard the impact that their decision has on the unskilled. This explains why $\tau^{L}>\tau^{S}$ (as well as $\tau^{L}>\tau^{O}$ ), as shown in Section 4 .

It remains to compare $\tau^{L}$ and $\tau^{M}$. The ranking is not a priori obvious because an individual skilled worker does not internalize the competition, variety and demand effects described in Section 3.1. Some tedious calculations show that

$$
\tau^{M}>\tau^{L} \quad \text { if and only if } \quad \frac{b}{c}>\frac{\sqrt{5}-1}{4} \frac{L}{\phi}
$$

Hence, when the competition effect is weak because $c$ is small, when the variety effect is strong because $b$ is large, and/or when the demand effect is strong because of the large number $\phi$ of skilled moving with their firm, then the market will result in agglomeration although the whole group of skilled workers prefers dispersion. Another simple, and perhaps more suggestive, way to say that $(22)$ holds is to assume that the population size $(L)$ of the skilled/mobile workers is 'small'. In this case, a single mover expects more than what she obtains when all the skilled move with her.

Since the unskilled as a whole always prefer dispersion, when (22) holds there exists a domain of trade cost values $\left(\tau^{L}<\tau<\tau^{M}\right)$ for which both groups of workers are worse off at the market agglomeration than at the dispersed configuration. This somewhat surprising result finds its origin in the

\footnotetext{
${ }^{7}$ We are grateful to Victor Norman for pointing out this property of linear demands.
} 
several pecuniary externalities that a skilled worker imposes on all workers when moving from one region to the other.

When (22) does not hold, the skilled remain dispersed although it is optimal for them to congregate for $\tau^{M}<\tau<\tau^{L}$. This is so when there are 'many' skilled/mobile workers in the economy, in which case the two groups of workers have conflicting interests. Whereas the skilled would benefit from a coordinating device that would lead them to agglomerate, the unskilled would be hurt by such a coordination.

\section{The lobbying game}

We now assume that a central authority (the European Commission) has the power to restrict the mobility of the skilled workers but does not have enough information to enforce the first and second best optima. Which interest groups are going to be formed and how can we expect them to influence the political choice between free mobility (denoted by $f$ ) and mobility barriers (denoted by $b$ ) for the skilled workers? In our setting, there are two natural interest groups that can be formed: (i) the skilled who are potentially mobile and (ii) the unskilled who are immobile. As seen in the foregoing, the former hurt the latter when they agglomerate into a single region.

Following Bernheim and Whinston (1986), we model the political process as an auction over alternative policies whose bidders are the interest groups. The auctioneer is the central authority which has no information about the welfare implications of policies and uses the bid offers to extract information about the lobbyists' valuations of the alternative policies. Hence, this a signalling game in which the two interest groups make offers, anticipating that the central authority will implement the policy that gets the higher bid. For simplicity, it is assumed that the first stage game is a game of complete information whose outcome is given by a (pure strategy) Nash equilibrium. Finally, we assume that bidding is 'competitive': both interest groups have free access to the bidding process, both face zero cost of collective action and the central authority simply acts as a neutral intermediator ('honest broker'). ${ }^{8}$

\footnotetext{
${ }^{8}$ In this respect, our framework differs from the common-agency approach developed since Grossman and Helpman (1994) who considers situations in which the access to the lobbying process is restricted to some interests only and the central authority is not a neutral intermediator but has personal preferences over the alternative policies.
} 
We already know that for $\tau>\tau^{L}$ both groups of workers are better off when there is dispersion. In this case, there is multiplicity of equilibria in which one group makes an arbitrarily small but strictly positive offer (when $\tau=\tau^{L}$ only the unskilled will make an offer). Regardless of the equilibrium outcome that emerges, the chosen policy, that is free mobility or mobility barriers, turns out to be socially optimal. When $\tau<\tau^{L}$, there is always a conflict between the two groups because the unskilled do not want the skilled to agglomerate. The winning group will be the group which enjoys the higher surplus relative to the alternative policy, respectively given by $W_{L}(f)-W_{L}(b)$ for the skilled and $W_{A}(b)-W_{A}(f)$ for the unskilled, where $W_{K}(s)$ is the welfare evaluated at the equilibrium prices (7)-(10) of the group $K \in\{L, A\}$ when the solution $s \in\{f, b\}$ is chosen. Clearly, in the equilibrium of the lobbying game, only the winning group bids and its offer is equal to the surplus of the other group. Hence, we have to determine under which conditions we have

$$
W_{L}(f)-W_{L}(b)>(<) W_{A}(b)-W_{A}(f)
$$

These inequalities are equivalent to

$$
W_{L}(f)+W_{A}(f)>(<) W_{L}(b)+W_{A}(b)
$$

which corresponds to the second best condition. As a consequence, it follows from Proposition 3 that the group of skilled will win the auction when $\tau<\tau^{S}$. On the other hand, when $\tau^{S}<\tau<\tau^{L}$, the auction will be won by the group of unskilled. In other words, in our model competitive lobbying leads to the second best optimum. ${ }^{9}$ This implies that a deepening of the integration process will favor the freeness of the skilled once trade costs have reached a value which is below $\tau^{S}$. Stated differently, moving toward sufficiently far in the direction of free trade is accompanied by a political process that spurs the mobility of the skilled workers and the formation of a core region.

Thus far, we have assumed that both groups of workers are organized on an interregional basis. This seems reasonable for the mobile workers but is less for the immobile. Allowing for cooperation between the skilled and the unskilled who reside in the region that becomes the core region does not

\footnotetext{
${ }^{9}$ Clearly, any violation of the 'competitive' assumption would lead to suboptimal policy choices. This would happen, for example, if (i) not all skilled or unskilled workers were members of their corresponding interest group, since different weights would be introduced in the above inequalities, (ii) if different interest groups faced different costs of collective action, (iii) if the central authority were not a neutral intermediator.
} 
affect our results, however. Indeed, if $H$ is the elected region, we have to compare $W_{L}(f)-W_{L}(b)+W_{A}^{H}(f)-W_{A}^{H}(b)$, the differential surplus earned by the skilled and the subgroup formed by the unskilled living in region $H$, to $W_{A}^{F}(b)-W_{A}^{F}(f)$ which represents the differential surplus of the unskilled in region $F$. Even if the values of the bids are not the same as before, the policy choice is still the same since the inequalities

$$
W_{L}(f)-W_{L}(b)+W_{A}^{H}(f)-W_{A}^{H}(b)>(<) W_{A}^{F}(b)-W_{A}^{F}(f)
$$

are again equivalent to (23). Of course, the whole burden of agglomeration is now on the shoulders of the traditional workers living in the peripheral region. Therefore, cooperation between the skilled and some unskilled has strong redistributive implications within the population of unskilled workers. More generally, this implies that, while the actual coalitions that are formed are crucial in terms of redistribution, they turn out to be immaterial in terms of efficiency.

\section{Concluding remarks}

Our model of agglomeration has allowed us to investigate the much debated question of whether or not the deepening of the integration process within the $\mathrm{EU}$ is going to lead to more concentration of economic activities, and when such an agglomeration is desirable from the collective standpoint. Our results suggest that there is no clear-cut answer. Indeed, too much agglomeration arises for intermediate values of the trade costs, while the market outcome is optimal for low or high values of these costs. However, there seems to be a need for an active regional policy within the EU if, as discussed in the introduction, the actual values of trade costs are not likely to become very low. This raises the question of the implementation of the desirable policy.

We concentrated here on imposing restrictions on factor mobility as a policy instrument to prevent undesired agglomeration. Assuming that the central authority has little or poor information about the welfare implications of alternatives decision, we have shown that, if interest groups are allowed to reveal their preferences through competitive lobbying, the political outcome may well foster a solution which is efficient. For such a mechanism to work, all interests should have free access to the bidding process, all should face the 
same cost of collective action and the central authority should simply act as a neutral intermediator.

In perspective, our analysis also yields potentially interesting insights on the issue of interregional transfers. First, the model suggests the existence of an upper bound on the amount of redistribution that could be performed without distorting efficiency. This level is equal to half of the difference between the relative surpluses attained by the winning and losing interest groups. Second, while, for simplicity, we have restricted our attention to factor mobility controls so that the potential scope of transfers is merely redistributive, inspired by the European experience one might wonder whether similar results could be attained by using only transfers also for shaping the efficient economic landscape. This should be possible in principle whenever equity and efficiency go hand in hand (no equity-efficiency trade-off). However, under both counts, the lack of information by the central authority would require some sort of more sophisticated mechanism design than our simple menu auction.

\section{References}

[1] Amiti M. (1998) New trade theory and industrial location in the EU : a survey of evidence, Oxford Review of Economic Policy 14, 45-53.

[2] Armstrong, H.W. and R.W. Vickerman, eds. (1995) Convergence and Divergence Among European Regions (London: Pion).

[3] Austen-Smith, D. (1993) Information and influence: Lobbying for agendas and votes, American Journal of Political Science 37, 799-833.

[4] Bernheim, B.D. and M.D. Whinston (1986) Menu auctions, resource allocation, and economic influence, Quarterly Journal of Economics 101, $1-31$.

[5] Davis, D.R. and D.E. Weinstein (1999) Economic geography and regional production structure: an empirical investigation, European Economic Review 43, 379-407.

[6] de la Fuente, A. and X. Vives (1995) Infrastructure and education as instruments of regional policy: evidence from Spain, Economic Policy 20, 13-51. 
[7] European Commission (1996) First Report on Economic and Social Cohesion (Luxembourg: Office for Official Publications of the European Communities).

[8] The Economist (1998) The Brussels lobbyist and the struggle for ear-time, August 15th, 25.

[9] Fujita, M., P. Krugman and A.J. Venables (1999) The Spatial Economy. Cities, Regions and International Trade (Cambridge (Mass.): MIT Press).

[10] Fujita, M. and J.-F. Thisse (1996) Economics of agglomeration, Journal of the Japanese and International Economies 10, 339-78.

[11] Gorges, M.J. (1996) Eurocorporatism? Interest Intermediation in the EC (London: University Press of America).

[12] Grossman, G. and E. Helpman (1994) Protection for sale, American Economic Review 84, 833-50.

[13] Head, K. and T. Mayer (1998) Non-Europe. The magnitude and causes of market fragmentation in the EU, Faculty of Commerce, University of British Columbia, mimeo.

[14] Horn, H. and O. Shy (1996) Bundling and international market segmentation, International Economic Review 737, 51-69.

[15] Krugman, P. (1991) Increasing returns and economic geography, Journal of Political Economy 99, 483-99.

[16] Martin, Ph. (1998) Regional policies, growth and geography in Europe, World Economy 21, 757-74.

[17] Martin, Ph. (1999) Public policies, regional inequalities and growth, Journal of Public Economics, forthcoming.

[18] Mazey, S. and J. Mitchell (1993) Europe of the regions? Territorial interests and European integration: The Scottish experience. In S. Mazey and J. Richardson, Lobbying in the European Community (Oxford: Oxford University Press), 95-121. 
[19] Mazey, S. and J. Richardson (1993) Introduction: Transference of power, decision rules, and rules of the game. In S. Mazey and J. Richardson, Lobbying in the European Community (Oxford: Oxford University Press), $3-26$.

[20] Michel, Ph., P. Pestieau and J.-F. Thisse (1983) Regional allocation of investment with distributive objectives, Journal of Regional Science 23, 199-209.

[21] Neven, D. and C. Goyette (1995) Regional convergence in the European Community, Journal of Common Market Studies 33, 47-65.

[22] Olson, M. (1980) The Logic of Collective Action (Cambridge (Mass.): Harvard University Press).

[23] Ottaviano, G.I.P. (1996) Monopolistic competition, trade, and endogenous spatial fluctuations, CEPR Discussion Paper $\mathrm{N}^{\circ} 1327$.

[24] Ottaviano, G.I.P. and D. Puga (1998) Agglomeration in the global economy: a survey of the 'new economic geography', World Economy 21, $707-31$.

[25] Ottaviano, G.I.P. and J.-F. Thisse (1998) Agglomeration and trade revisited, CEPR Discussion Paper $\mathrm{N}^{\circ} 1903$.

[26] Ottaviano, G.I.P. and J.-F. Thisse (1999) Monopolistic competition, multiproduct firms and optimum product diversity, CORE Discussion Paper $\mathrm{N}^{\circ} 9919$.

[27] Potters, J. and F. van Winden (1992) Lobbying and asymmetric information, Public Choice 74, 269-292.

[28] Rahman, M.A. (1963) Regional allocation of investment, Quarterly Journal of Economics 77, 26-39.

[29] Sala-i-Martin, X. (1996) Regional cohesion: evidences and theories of regional growth and convergence, European Economic Review 40, 132552 .

[30] Shields, G.M. and M.P. Shields (1989) The emergence of migration theory and a suggested new direction, Journal of Economic Surveys 3, 277-304. 
[31] Takayama, A. (1967) Regional allocation of investment: a further analysis, Quarterly Journal of Economics 81, 330-37.

[32] Tirole J. (1988) The Theory of Industrial Organization (Cambridge (Mass.): MIT Press).

[33] World Bank (1999) World Development Report 1999/2000 (Washington, D.C., forthcoming). 


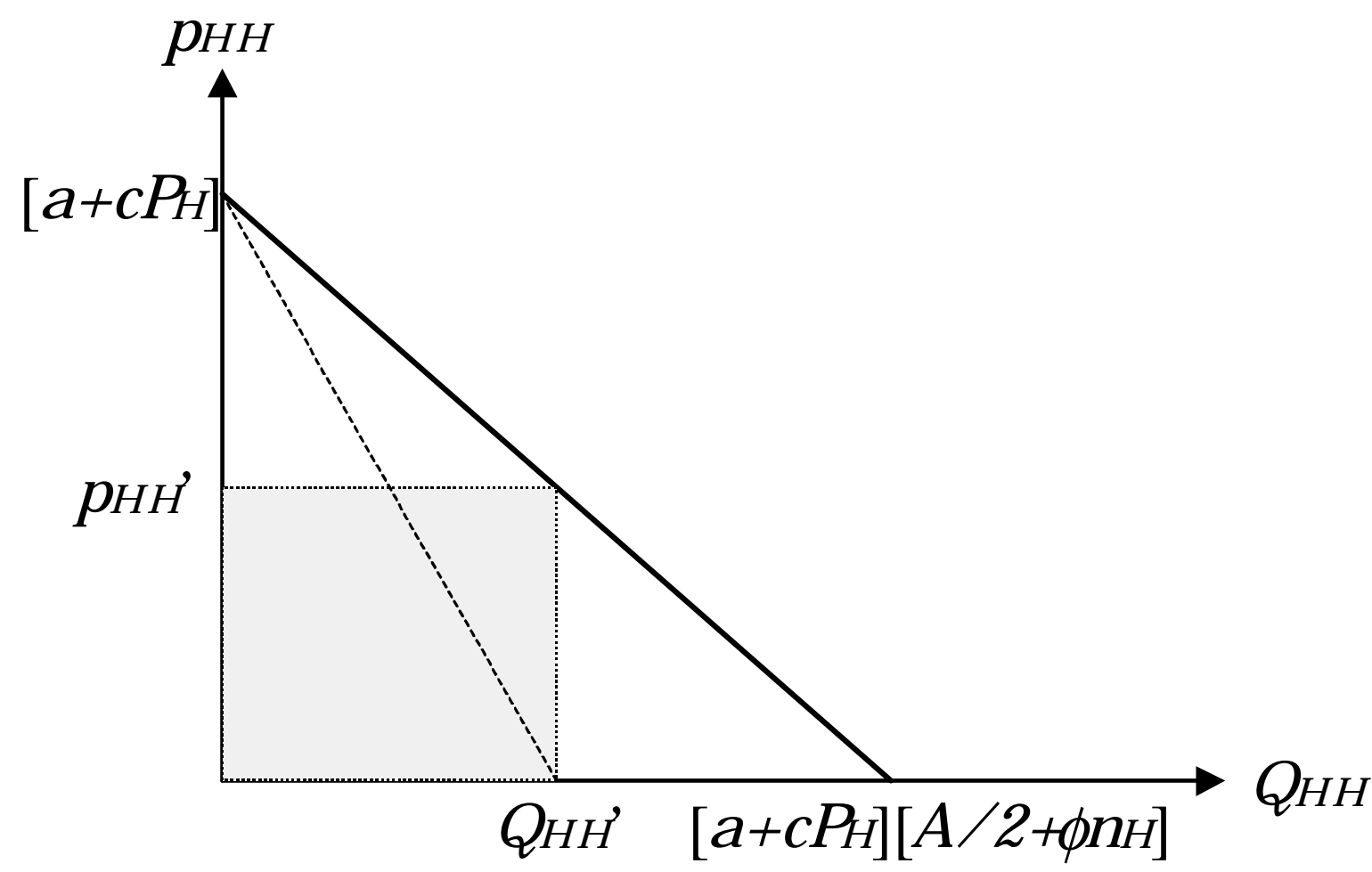

Figure 1: Inverse demand 


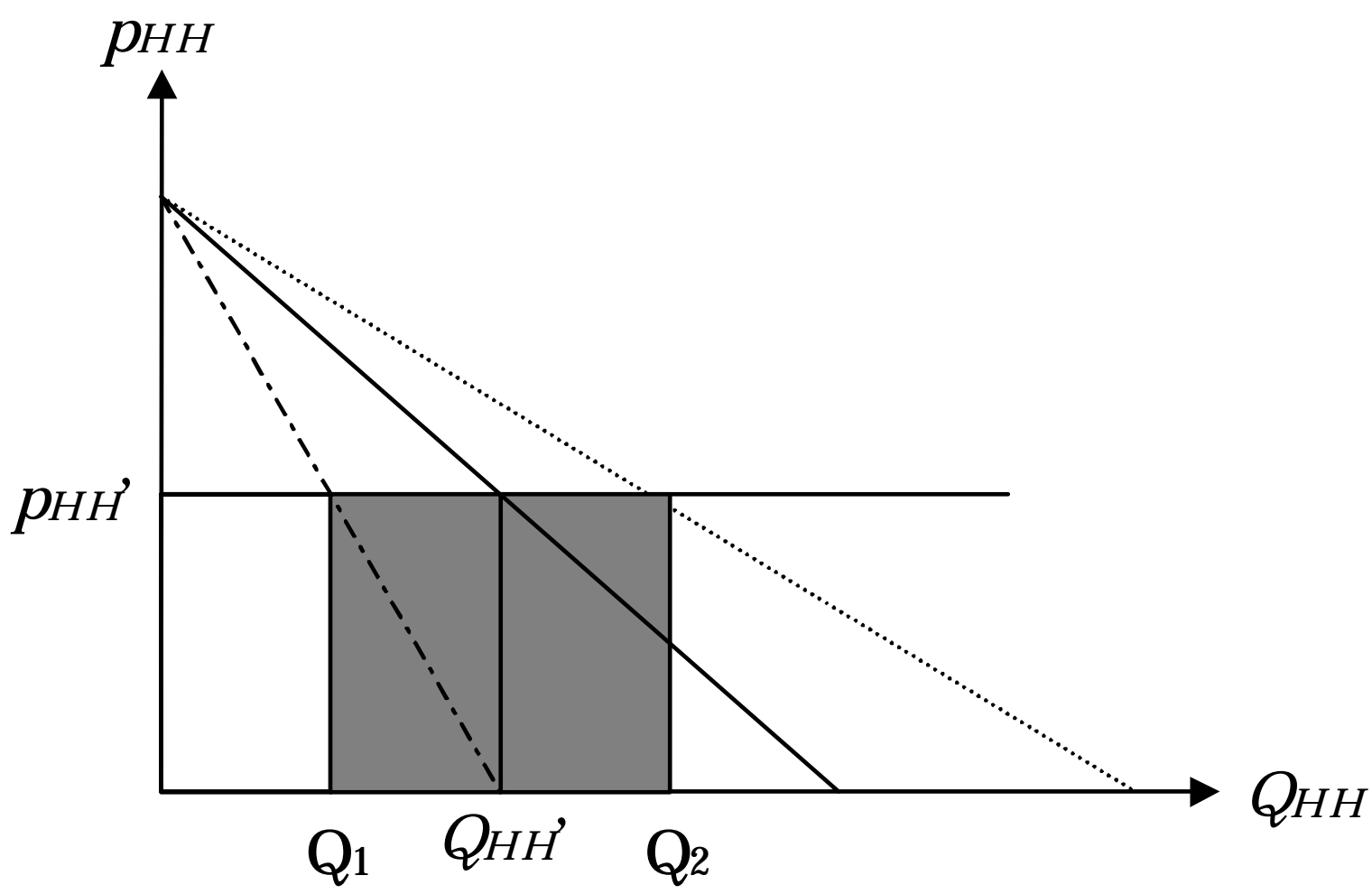

Figure 2: Demand effects 